\title{
Names, Identity, and Self
}

\section{KENNETH L. DION ${ }^{1}$}

\begin{abstract}
Along with other scholars, some psychologists have proposed a relationship between a person's name and her or his sense of identity and self. The evidence concerning this proposition, drawn from several areas of psychology, is the subject of this paper. Studies of (a) personal identity, (b) names and self-acceptance, and (c) attention and memory for one's name, respectively, are presented and discussed. This diverse research leads to the conclusion that names, identity, and self are indeed closely related.
\end{abstract}

\section{Les Noms, L'Identité, et Le Soi}

Comme d'autres savants, quelques psychologues ont proposée un lien entre le nom d'une personne, son sens d'identité, et son sens de soi. L'évidence pour cette proposition, qui est tirée de plusieurs domaines de psychologie, est le sujet de cette discussion. Je propose à présenter et à discuter les études sur (i) l'identité personelle, (ii) les noms et i'acceptance de soi, et (iii) l'attention que nous portons et la mémoire que nous employons pour le nom de soi-même. Ces études de recherche divers nous conduit à la conclusion que les noms, l'identité, et le soi sont, en effet, étroitement liés.

$\mathrm{I}_{\mathrm{n}}$

this paper, I re-state and elaborate in greater depth one theme discussed in a brief, recent overview of research on the psychology of names (Dion, 1982): The notion that a close connection exists between an individual's name and her/his personal identity and sense of self. The contention that names are linked to identity is hardly a new idea, even for psychologists. For some years now, psychologists have been proposing that the name given a person influences the identity she/he develops.

In a classic treatise on the psychology of ego-involvement, Muzafer Sherif and Hadley Cantril (1947) stated a very similar hypothesis and considered some of its psychological implications. For example, they suggested that during infancy, the child "learns . . . its name and around this name . . gathers many characteristics that define . . psychological identity" (Sherif \& Cantril, 1947, p. 199). These authors also reported a number of interesting observations testifying to the apparent importance individuals and societies attach to names (see, for example, pp. 352356).

'Correspondence and requests for reprints should be sent to Kenneth L. Dion; Department of Psychology; University of Toronto; Toronto, Ontario; Canada M5S 1A1

Names, 31, No. 4 (December 1983) 
In a similar vein, the personality theorist Gordon Allport (1961) contended that one's name is the focal point upon which self-identity is organized over the course of an individual's life. More recently, in the context of a psychological theory of uniqueness, C. R. Snyder and Howard Fromkin (1980) proposed that names, along with commodities as well as attitudes and beliefs, are "uniqueness attributes" through which individuals may differentiate themselves from other persons.

However, what evidence exists to support these theoretical contentions? Those who have speculated that names are related to identity, myself included, have not usually themselves gathered the psychological data necessary to test their conjectures. Nor have other investigators conducted studies explicitly designed to assess these theories.

Yet, a careful search of the psychological literature does reveal instances of research with clear bearing for the central premise of this paper. In most cases, these studies were conducted to investigate issues other than those directly concerning the psychology of names. Nevertheless, their findings lend some solid credence to the notion that self and identity are closely bound to name. It is this otherwise disparate and unorganized social-psychological evidence concerning names that is the focus of this paper.

\section{STUDIES OF IDENTITY}

The most direct evidence relating names to identity comes, perhaps not surprisingly, from psychological and sociological investigations of personal identity. In this line of research, various procedures have been developed to explore aspects of an individual's sense of personal identity. A classic and still frequently employed technique is to ask respondents to answer questions such as "Who Are You?" or "Who Am I?" some number of times.

In the first investigation of this kind, personality psychologists James Bugental and Seymour Zelen (1950) asked men and women, including a large "core" group of college students as well as smaller comparison groups of mature adults not attending university, to provide three answers to the question: "Who Are You?" Classifying responses from the "core" college group into 17 different categories revealed that reference to one's own name was the single, most frequent type of response, easily outnumbering references to all other categories except sex and occupation. Specifically, $63 \%$ of the college student respondents made explicit reference to their names when indicating who they were. Name references accounted for $18.1 \%$ of all college student responses and $16.5 \%$ of the answers 
from all respondents overall. In addition, comparisons by sex between the "core" college group and the mature non-college groups showed no differences in the frequency of references to names. Taking these findings together, Bugental and Zelen (1950, pp. 493 \& 496) concluded that name is a " . . . central aspect of the Self-Concept."

The sociologists Manford Kuhn and Thomas McPartland subsequently modified Bugental and Zelen's procedure by having subjects respond to the question "Who Am I?" as if they were answering themselves rather than someone else and to do so 20 times within a specified interval (Kuhn $\&$ McPartland, 1954; Kuhn, 1960). The resulting measure of identity was appropriately dubbed, and has since been known as, the Twenty-Statements Test (TST). Changing the question posed from "Who Are You?" to "Who Am I?" should logically decrease the frequency of name references since, obviously knowing their own names, respondents would be less likely to cite it as a pertinent aspect of themselves. Yet, studies using the Twenty-Statements Test or variations of the "Who Am I?" technique for assessing identity, with samples of people of different ages, still show the influence of names upon personal identity.

Sociologist Chad Gordon (1968), for example, administered the Twenty-Statements Test to several groups, including a high school student sample as well as samples of Los Angeles City College and HarvardRadcliffe college sudents. Respondents' protocols were classified according to a comprehensive system of self-reference categories devised by Gordon, including one for names. Commenting on the latter category, Gordon (1968, p. 125) noted: “ . . . an individual's name . . . serves as his [her] more or less unique 'identity peg,' it also locates him [her] in his [her] family and serves as a handy indication of his [her] sex." Justifying the category for names, it was found that $17 \%$ of the high school student sample and approximately $30 \%$ of both college student samples referred to their names at least once when giving 20 answers to the question "Who Am I?" Moreover, among the Harvard-Radcliffe students who made reference to their name in describing themselves, it was typically the first response mentioned, perhaps suggesting the importance attached to the dimension.

Similarly, using the "Who Am I?" technique and Gordon's category system, developmental psychologists Raymond Montemayor and Marvin Eisen (1977) explored the changes in self-conception during adolescence of a sample of white, upper-class mid-America youth. Curvilinear age changes were found for the categories of name, sex, and kinship rolestatuses. In particular, the percentages of respondents referring to their names in describing themselves were $50 \%, 8 \%$, and $31 \%$ for the ages of 
10,14 , and 18 , respectively. Also, in the protocols these investigators provided as typical self-descriptions, younger children mentioned their names first of the twenty items.

Names and spontaneous self-concept. Yale University psychologist William McGuire and his colleagues have devised an alternative method to the Who-Are-You? and Twenty-Statements Test for determining the way individuals perceive themselves, as part of a research program for testing their distinctiveness theory of self-perception. According to this theory, a person taking a complex stimulus such as the self as an object of perception notices her/his distinctive traits and personal characteristics more readily because of their greater informational richness and value for discriminating self from others. Thus, for example, for a red-headed person in a family or group otherwise composed exclusively of brunettes, the relatively distinctive quality of "redheadedness" should be a salient feature of that individual's self-perceptions and spontaneous self-concept.

As tests of this perspective, McGuire and his associates have analyzed the content of children's written or oral answers to being asked to "tell us about yourself." Evidence from several studies strongly confirms the distinctiveness theory of self-perception, in that children tend to cite their more distinctive characteristics in spontaneously describing themselves. Although they have yet to focus directly on names, some of their prior research nevertheless suggests that names are, in fact, a salient element of individuals' self-perceptions.

Specifically, in a study by McGuire and Padawer-Singer (1976), sixthgraders were asked to write their self-descriptions with instructions not to indicate their names anywhere in the booklets in order to insure their anonymity. Despite that instruction and its likely inhibiting effect upon noting one's name, their names were apparently of sufficient importance to their sense of who they were that $19 \%$ of the children still indicated them. McGuire and Padawer-Singer (1976, p. 748) ventured the following speculation: "Probably an even larger proportion think of their names as a salient part of their self-concept, but their giving names here was depressed due to the explicit instruction regarding anonymity."

It thus remains a task for future research with this technique to accurately gauge the salience of names in spontaneous self-concept relative to other traits and personal characteristics. Since the distinctiveness of names can be easily indexed in terms of their frequency relative to various reference groups, names are an obviously pertinent and potentially interesting dimension for advocates of the distinctiveness theory of selfperception. Both with regard to the way we presumably see ourselves and others as well as the way others see us, McGuire's distinctiveness theory would predict that one's name will be salient to the extent it is distinctive 
relative to habitual or even transient reference groups (McGuire, McGuire, \& Winton, 1979). In other words, this perspective implies that our names are salient to ourselves and to others, especially when they are relatively infrequent and therefore distinctive in the context of groups of which we are members.

Names and the development of self-identity. The preceding research has been largely concerned with the relationship of names to identity among adults and adolescents. In this section, our attention focuses on the role of names in the development of self-identity during childhood and infancy.

In one of these studies, Carol Guardo and Janis Bohan (1971) interviewed a sample of white, middle-class American children between 6 to 9 years of age and posed them questions probing different aspects of their sense of self-identity. For example, to explore their sense of personal continuity over time, each child was asked whether she/he had been the same person since birth and whether she/he would be the same person in the near and remote future. The children were also asked whether they would remain the same person if their names were taken away.

As Guardo and Bohan (1971) and other developmentalists commenting on this research (Hoffman, 1976, p. 136) have noted, overall the results indicated that the main underpinnings of the children's self-identity, throughout the age range studied, were names, physical characteristics, and behavior. Approximately $80 \%$ of the children indicated names, physical characteristics, and behavior as the "essential anchorage points" of their personal identities.

In particular, names played a prominent role in the children's sense of personal continuity over time. Many children predicated their feeling of continuity from the past to the present and into the future on the fact of retaining the same name. Younger children were especially apt to base their sense of being the same person on having an unchanging name. Perhaps not coincidentally, younger children were also prone to "nominal realism" - a naive belief that something cannot exist without its name (Piaget, 1965). The susceptibility of younger children to such a belief is shown by the fact that slightly more than a quarter of the 6- and 7year-old children in Guardo and Bohan's (1971) sample felt they would not be the same person if their name was removed. In contrast, only about $5 \%$ of the 8- and 9-year-old children believed that their self-identity was inextricably bound to their possession of a particular name. ${ }^{2}$

\footnotetext{
2Yet, even adults may believe in "nominal realism", as shown by Robert Holt's (1939) study of 30 adult persons from different backgrounds. As part of extensive interviews concerning names, Holt asked his respondents: "Can you imagine being named anything else and being the same person that you are?" Most respondents reported they could not imagine being the same person with a different name.
} 
Other explorations of the development of self-identity strongly suggest that the psychological link between names and personal identity is forged early in infancy. For example, in one study by Michael Lewis and Jeanne Brooks-Gunn (1979), infants aged 15, 19, and 22 months were presented with slides of pictures of adults and infants, including themselves. For each picture, the infant was asked "Who is that?" by its mother and prompted once in the absence of a response, but not corrected when in error.

Use of own name and personal pronouns as verbal labels for pictures of themselves was taken by the investigators as an indication of self-recognition. ${ }^{3}$ Notably, of the verbal infants who labeled pictures of themselves, $63 \%$ used their own name. No infant used any other person's name to label a self-picture. Using own name to label a picture of themselves also tended to increase with the age of the infant, with $50 \%$ of the 15 -month group, $60 \%$ of the 19 -month group, and $67 \%$ of the 22 -month group doing so.

In another study of infants' verbal labels of pictures, Lewis and BrooksGunn (1979, pp. 150-159) also included older infants between 18 and 36 months of age. For that investigation as well, better than two-thirds of the verbal infants labelled pictures of themselves, and primarily only selfpictures, with their own names.

One can perhaps ask whether the infants' verbalizations of their name or personal pronouns in response to a picture of themselves does indeed reflect self-recognition and a sense of self-identity. Lewis and BrooksGunn $(1979$, p. 162) believe that it does, noting that " . . . infants who use a self-referent to label pictures ... . often point to themselves or examine their clothing at the same time."

Summary. In the preceding sections, the question of the relationship of names to self-identity has been considered from the view of socio/psychological studies using a wide variety of techniques for assessing personal identity. Although each technique, considered alone, is undoubtedly fallible to some extent as a reflection of self-identity (see Wylie, 1974, pp. 240-247 for a critique of the TST, for example), the convergence of several, different procedures in suggesting a link between names and selfidentity and at different ages strongly corroborates theories predicting or assuming such a connection to exist. The existing research also clearly suggests that one's name is an important, early foundation for the devel-

\footnotetext{
${ }^{3}$ There is a time-honored tradition for doing so. Preyer in the 1890 's and the pioneering sociologist, Cooley, in the early 1900's were the first investigators to rely upon the infant's verbalizations of its own name and self-referent pronouns in order to chart the development of self-identity (Holt, 1939).
} 
opment of self-identity in infancy and childhood and then declines somewhat for this purpose during adolescence. An association between names and identity is also present in early and middle adulthood, though estimates of its strength vary.

Having discussed the studies of personal identity, let us now consider other lines of psychological research that further strengthen our conclusions of an intimate relationship between names, identity, and self. Toward this end, studies of the relationship of names to self-acceptance are presented. Finally, some provocative research concerning attention and memory involving one's name is discussed.

\section{NAMES AND SELF-ACCEPTANCE}

Identity and self-acceptance are different, though related, psychological concepts. Identity refers to a person's sense of who or what she/he is. Self-acceptance or self-esteem concerns an individual's evaluation or overall liking-disliking of themselves. It seems reasonable to assume that one's sense of identity and the extent of one's self-acceptance would tend to co-vary with one another. Similarly, from the idea of a close tie between one's name and one's self, self-acceptance and liking for one's own name would be expected to correlate positively with one another, such that greater liking for one's own name is associated with stronger acceptance of self.

Several studies support these conjectures. For example, in his doctoral dissertation research, Daniel Adelson (1957) had college and high-school students complete a self-acceptance scale, a measure of attitudes toward own first name, and likability ratings of the first names of everyone in the sample. Individuals who liked their own name tended to identify more strongly with it, in the sense of affirmatively answering the question: "Do you feel your first name is you?' Furthermore, individuals who either liked their first names or were neutral toward them scored higher on the self-acceptance scale than those who expressed dislike of their first names.

Other studies provide additional confirmation of an association between liking one's name and liking one's self. For example, Orville Strunk (1958, also cited by Allport, 1961) similarly found that people who liked their own first names also liked themselves more generally. Another investigation by Roger Boshier (1968) with adolescent boys and girls in New Zealand obtained high positive correlations between their scores on a standard self-esteem inventory and whether or not the youths liked their first names.

Since a name is, after all, a part of one's self, it may not be entirely 
surprising to find strong, positive relationships between names and selfacceptance. What is perhaps less obvious is the capacity of own name to draw one's attention, even under difficult conditions, presumably because of its emotional and symbolic significance.

\section{NAMES AND ATTENTION}

It is usually assumed that we are especially attentive to events of emotional significance to us. Mothers, for example, are believed to be exceptionally sensitive to the sound of their own child crying. Similarly, people often report being able to hear someone mention their name in the midst of a noisy cocktail party (Moray, 1959; Allport, 1961) or even when they are sleeping. Research by experimental psychologists suggests the latter phenomena are real and that they reflect the attention-eliciting value of names.

Moray (1959) was perhaps first to demonstrate experimentally the potency of a name as an attention-eliciting device, using a procedure devised by Cherry (1953) known as "shadowing" for studying the process of attention during dichotic (i.e., "two ear") listening. In this procedure, the subject dons headphones through which different auditory information can be presented to each ear simultaneously. In one earphone, she/he hears a continuous, prose passage and is asked to "shadow" it by repeating it aloud as it is presented. Shadowing a message in this manner typically creates a selective attentional barrier that largely blocks apprehension of material presented to the other ear or "unattended channel.",

Thus, a subject engaged in shadowing is usually aware of the presence, but not the content or meaning, of information presented to the unattended channel (Cherry, 1953; Swets \& Kristofferson, 1970). For example, the shadower may notice gross alterations in the physical properties of auditory stimuli in the unattended channel (e.g. changes from a female voice to a male one or from a voice to a tone), but not shifts in the verbal content of what is said (as, say, a speaker switching from one language to another). As a result, the information presented in the unattended channel is often referred to as the "rejected" message.

For his part, Moray (1959) first verified for himself the preceding observations of a selective attentional barrier due to shadowing. In an initial experiment, he presented a list of simple words to one ear of his subjects and repeated it 35 times while they shadowed a prose passage presented to the other ear. Immediately after, they were asked to report as much of the content of the rejected message as they could and were also given a word recognition test. There was little evidence to indicate 
subjects had retained any information from the rejected message. Words from the shadowed passage, on the other hand, were readily recognized.

Moray's (1959) subsequent experiment is particularly germane to our discussion. In the second experiment, subjects shadowed ten short prose passages and received instructions in the unattended channel. Half the time these instructions were preceded by mentioning the subjects' full names (i.e., their first and last names). Instructions from the rejected message were much more likely to have been heard by subjects when their names were mentioned. Moray concluded that an otherwise formidable attentional barrier from shadowing could be penetrated by making reference to a person's name and attributed this effect to the "affective value" and "importance" of one's name for the individual.

Moray's (1959) conclusions are weakened, unfortunately, because only the subjects' own names were employed. Thus, from this experiment alone, we cannot be certain that it is one's own name, rather than, say, people's names generally, that possesses the attention-arousing property he observed. Other investigators, however, have avoided this problem by including both own and other people's names as stimuli in their studies of attention and audition.

Howarth and Ellis (1961), for example, explored the relative ease (i.e., the auditory thresholds) for perceiving one's own name compared to other names. Subjects wearing headphones were presented at spaced intervals with numbers between 1 and 100 in one channel and simultaneously with repetitions of ten first names of men and women, including their own, in the other channel. A masking sound was also added to both channels to provide a constant level of "noise." Subjects recognized their own names $77 \%$ of the time and the other names on only $50.5 \%$ of the presentations. Thus, it is indeed easier to hear one's own name than other names in a "noisy" and potentially distracting situation.

However, perhaps the most intriguing experiment illustrating the attention-eliciting power of one's own name was conducted by Ian Oswald, Ann Taylor, and Michel Treisman (1960), a physiologist and two psychologists then affiliated with Oxford University in England. An audiotape recording, on which 56 male and female first names were "urgently" spoken every several seconds, was played to volunteers while they were sleeping moderately deeply after having been deprived of a previous night's rest. Prior to falling asleep, they had been instructed to awaken and clench a fist whenever they heard their own name and one other "control" name.

Hand movements were observed on $25.2 \%$ of the occasions the subjects' own name was presented and for $12.1 \%$ of control name presentations. In contrast, the ten other names preceding mention of own or 
control names elicited much lower rates of hand movements: $1.28 \%$ and $1.65 \%$, respectively. Thus, even in medium sleep, individuals are more apt to respond to their own name than to other names, including a control one.

Oswald and his colleagues also obtained electroencephalographic (EEG) records (i.e., recordings of the electrical activity of the brain) while the volunteers slept. The K-complex from the EEG record is another index of responsiveness to stimuli that reflects the extent of physiological activity provoked by a sensory event. As with hand movements, the proportion of K-complexes in the EEG record observed in response to own name $(66.4 \%)$ was almost twice as great as that for another name that immediately preceded it $(33.6 \%)$ and also greater than that for the control name (44\%).

The preceding experiments make a convincing case that mention of one's name by others has considerable power to elicit the individual's attention, presumably because of its special significance to the bearer of the name. Names, of course, serve as a symbolic representation of the selves we present to others. As such, it is entirely plausible that we would be especially attentive to its mention by them.

It is also interesting to ponder at precisely what age one's name first acquires its attention-arousing capability. Charles Fisher (1945, p. 461), a psychoanalyst, has speculated that: "An infant as young as six months will respond to its name." This observation, however, apparently remains to be validated experimentally, at least as far as auditory recognition is concerned (Trehub, personal communication).

\section{NAMES AND MEMORY FOR SELF-RELEVANT INFORMATION}

As a specialist in amnesic states in which individuals cannot remember who, what, and/or where they are, Fisher (1945, p. 462) also suggested that: "The name is . . . a kind of monogram for the sum total of a person's memories . . . of affective significance." This observation received some indirect support from a recent, quantitative case study of functional retrograde amnesia (Schacter, Wang, Tulving, \& Freedman, 1982). Functional retrograde amnesia can be defined as the forgetting of autobiographical and other information prior to a critical or traumatic event and due to psychological rather than organic causes.

Daniel Schacter and his colleagues investigated the memory impairments of a person suffering from functional retrograde amnesia who, for several days, could not remember his own name or other details of his personal past except the knowledge of previous employment with a courier service and his nickname while in that job. This individual com- 
pleted a series of memory tasks and his performance was compared to a closely matched "control" subject. The critical memory task consisted of an "autobiographical cueing procedure" in which they were given a typical English word by the experimenter and required to remember some prior, personal experience related to it and to date the episode.

Compared to the control individual, the person while suffering the amnesia remembered fewer personal episodes that had occurred prior to the onset of the amnesic state, especially in response to affective word cues, and was also slower in doing so. Most of the "episodic memories" (Tulving, 1972) he successfully retrieved during the amnesic phase came from his period with the courier service, when he had been relatively happy and also nicknamed "Lumberjack."

In thinking about the possible role of the nickname in triggering an "island" of episodic memories during the amnesic phase in this case, Schacter and his associates conjectured more broadly that one's name may serve as a "control element" determining access to information about our identity and past experiences of a personal, autobiographical nature in memory. As they put it: "It is possible to think of one's name as constituting the "ultimate control element' of episodic memory." This notion, that our memories for personal and self-relevant information might be organized around our names and accessed by means of them, is an intriguing one worthy of further investigation.

\section{CONCLUSION}

Taken all together, the several lines of research reviewed above strongly suggest the existence of psychological connections among names, identity, and self. The diverse research also illustrates several interesting techniques, including both "paper-and-pencil" questionnaire measures as well as experimental procedures, available to researchers interested in further pursuing these connections.

Several issues raised by the existing research obviously warrant more attention. For example, better estimates of the strength of the association between names and identity across the life cycle, especially in adulthood, are needed. Nor is it clearly known what factors influence the strength of the name-identity association. The preceding studies provide some interesting leads worth exploring in this latter regard.

As noted earlier, for example, McGuire's theory of selective perception would suggest the distinctiveness of one's name as one relevant factor. A person's sex may be yet another dimension influencing the association between names and identity. The results of Howarth and Ellis' (1961) study of auditory recognition clearly indicated that the tendency to 
perceive one's own name more readily than others' names was more characteristic of men than women. Since their sample was small, though, this sex difference merits further checking.

In any case, this and other interesting issues concerning names, identity, and self await investigation.

\section{The University of Toronto}

\section{REFERENCES}

Adelson, D. Attitudes toward first names: An investigation of the relation between self-acceptance, self-identity and group and individual attitudes toward first names. Dissertation Abstracts, 1957, 17, 1831. - Abstract.

Allport, G. W. Pattern and growth in personality. New York: Holt, Rinehart and Winston, 1961.

Boshier, R. W. "Self-esteem and first names in children." Psychological Reports 1968, 22, 761.

Bugental, J. F. T., \& Zelen, S. L. "Investigations into the 'self-concept' I. The W-A-Y technique." Journal of Personality, 1950, 18, 483-498.

Cherry, E. C. "Experiments on the recognition of speech with one and two ears." Journal of the Acoustical Society of America, 1953, 25, 975-979.

Dion, K. L. "The psychology of names." In B. B. Wolman (Ed.), International Encyclopedia of Psychiatry, Psychology, Psychoanalysis, \& Neurology, Progress Volume. New York: Aesculapius Publishers, 1982.

Fisher, C. "Amnesic states in war neuroses." Psychoanalytic Quarterly, 1945, 14, 437-468.

Gordon, C. "Self-conceptions: Configurations of content." In C. Gordon \& K. J. Gergen (Eds.), The self in social interaction, Volume I: Classic and contemporary perspectives. New York: John Wiley \& Sons, Inc., 1968, Pp. 115-136.

Guardo, C. J., \& Bohan, J. B. "Development of a sense of self-identity in children." Child Development, 1971, 42, 1909-1921.

Hoffman, M. L. "Empathy, role-taking, guilt, and development of altruistic motives." In T. Lickona (Ed.), Moral development and behavior. New York: Holt, Rinehart and Winston, 1976.

Holt, R. R. Studies in the psychology of names. Unpublished undergraduate thesis, Princeton University, 1939.

Howarth, C. I., \& Ellis, K. "The relative intelligibility threshold for one's own name compared with other names." Quarterly Journal of Experimental Psychology, 1961, 13, 236-239.

Kuhn, M. H. "Self-attitudes by age, sex, and professional training." The Sociological Quarterly, $1960,9,39-55$.

Kuhn, M. H., \& McPartland, T. A. "An empirical investigation of self-attitudes." American Sociological Review, 1954, 19, 68-76.

Lewis, M., \& Brooks-Gunn, J. Social cognition and the acquisition of self. New York \& London: Plenum Press, 1979.

McGuire, W. J., McGuire, C., \& Winton, W. "Effects of household sex composition on the salience of one's gender in the spontaneous self-concept." Journal of Experimental Social Psychology, 1979, 15, 77-90.

McGuire, W. J., \& Padawer-Singer, A. "Trait salience in the spontaneous self-concept." Journal of Personality and Social Psychology, 1976, 33, 743-754.

Montemayor, R., \& Eisen, M. "The development of self-conceptions from childhood to adolescence." Developmental Psychology, 1977, 13, 314-319.

Moray, N. "Attention in dichotic listening: Affective cues and the influence of instructions." Quarterly Journal of Experimental Psychology, 1959, 11, 56-60. 
Oswald, I., Taylor, A. M., \& Treisman, M. "Discrimination responses to stimulation during human sleep." Brain, 1960, 83, 440-453.

Piaget, J. The child's conception of the world. Patterson, N.J.: Littlefield, Adams, 1965.

Schacter, D. L., Wang, P. L., Tulving, E., \& Freedman, M. "Functional retrograde amnesia: A quantitative case study." Neuropsychologia, 1982, 20, 523-532.

Sherif, M., \& Cantril, H. The psychology of ego-involvements: Social attitudes and identifications. New York: John Wiley \& Sons, Inc., 1947.

Snyder, C. R., \& Fromkin, H. L. Uniqueness: The human pursuit of differences. New York: Plenurn Press, 1980.

Strunk, O. "Attitudes toward one's name and one's self." Journal of Individual Psychology, 1958, $14,54-67$.

Swets, J. A., \& Kristofferson, A. B. Attention. Annual Review of Psychology, 1970, 21, 339-366.

Trehub, S. E. Personal communication, May 1982.

Tulving, E. "Episodic and semantic memory." In E. Tulving \& W. Donaldson (Eds.), Organization of memory. New York: Academic Press, 1972.

Wylie, R. C. The self-concept. Lincoln, Nebraska: University of Nebraska Press, 1974. 